\title{
Substrate Plasticity of a Fungal Peptide $\alpha-N$-Methyltransferase
}

\author{
Haigang Song, ${ }^{\ddagger}$ Juratè Fahrig-Kamarauskaitè, ${ }^{\ddagger}$ Emmanuel Matabaro, Hannelore Kaspar, Sally L. Shirran, \\ Christina Zach, Amy Pace, Bozhidar-Adrian Stefanov, James H. Naismith,* and Markus Künzler*
}

Cite This: ACS Chem. Biol. 2020, 15, 1901-1912

Read Online

ACCESS |

Llll Metrics \& More

Article Recommendations

Supporting Information

ABSTRACT: The methylation of amide nitrogen atoms can improve the stability, oral availability, and cell permeability of peptide therapeutics. Chemical $N$-methylation of peptides is challenging. Omphalotin A is a ribosomally synthesized, macrocylic dodecapeptide with nine backbone $\mathrm{N}$-methylations. The fungal natural product is derived from the precursor protein, OphMA, harboring both the core peptide and a SAM-dependent peptide $\alpha-N$ methyltransferase domain. OphMA forms a homodimer and its $\alpha-N$ methyltransferase domain installs the methyl groups in trans on the hydrophobic core dodecapeptide and some additional C-terminal residues of the protomers. These post-translational backbone $\mathrm{N}$ methylations occur in a processive manner from the $\mathrm{N}$ - to the $\mathrm{C}$ terminus of the peptide substrate. We demonstrate that OphMA can

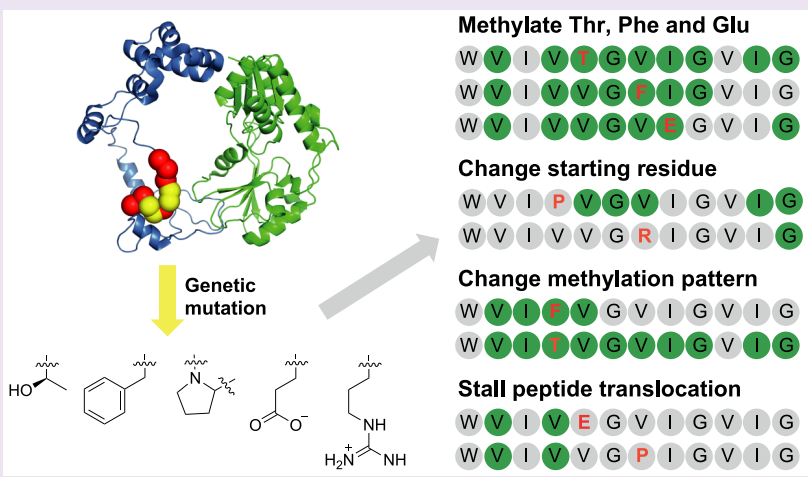
methylate polar, aromatic, and charged residues when these are introduced into the core peptide. Some of these amino acids alter the efficiency and pattern of methylation. Proline, depending on its sequence context, can act as a tunable stop signal. Crystal structures of OphMA variants have allowed rationalization of these observations. Our results hint at the potential to control this fungal $\alpha$ - $N$ methyltransferase for biotechnological applications.

\section{INTRODUCTION}

Peptide macrocyclization offers a way to increase peptide stability, membrane permeability, and rigidity. ${ }^{1}$ Chemical modifications do likewise ${ }^{2}$ and include exocyclic amide bonds, ${ }^{3}$ D-amino acids, ${ }^{4-7}$ tailoring of side chains, ${ }^{4,8,9}$ and backbone $(\alpha$ - $) N$-methylation. ${ }^{10-14}$ Backbone $N$-methylation is particularly potent, because it alters the energetic landscape of backbone dihedral angles (profoundly impacting the peptide secondary structure), ${ }^{15}$ shifts the amide bond cis/trans equilibrium, disrupts hydrogen bonding, ${ }^{12}$ reduces hydrophilicity of the amide backbone, and, in the macrocyclic peptide cyclosporine A, allows "shape shifting". ${ }^{12,16}$ Methylation is highly desirable for peptide therapeutics, since these properties influence metabolic stability, cell permeability, oral availability, and target selectivity. ${ }^{11}$

Conditions for chemical $N$-methylation of backbone amides often result in epimerization of amino acids, removal of protecting groups, and other unwanted side reactions. ${ }^{12,17-19}$ Thus, a biotechnological method of $N$-methylation would be very valuable. Omphalotin A (Figure 1A), a nematotoxic macrocyclic dodecapeptide natural product from the fungus Omphalotus olearius, contains nine backbone $N$-methylations. $^{20,21}$ For many years, omphalotin A was believed to be produced via nonribosomal peptide synthesis (NRPS). However, the peptide and its derivatives ${ }^{22,23}$ are derived from a ribosomally synthesized precursor protein that is processed by an enzymatic cascade comprising an $S$ - adenosylmethionine (SAM)-dependent peptide $\alpha$-N-methyltransferase domain of the precursor protein (OphMA), a prolyl oligopeptidase (OphP), member of the structurally characterized POP family of macrocycle forming enzymes, an acetyl transferase (OphD), and at least two cytochrome $\mathrm{P} 450$ monooxygenases (OphB1 and OphB2) (Figure 1B). ${ }^{24,25}$ OphMA consists of the N-terminal peptide $\alpha$ - $N$-methyltransferase domain (NMT, residues 1-251), a clasp domain (residues 252-378), and the C-terminal substrate peptide (residues 379-417). ${ }^{26,27}$ The precise boundary between the clasp and C-terminal substrate peptide is somewhat arbitrary. The C-terminal substrate peptide is subdivided into a leader sequence (residues 379-399), the core peptide which becomes omphalotin (residues 400-411), and a C-terminal recognition sequence (residues 412-417) (see Figures $1 \mathrm{~B}$ and $1 \mathrm{C}$ ). The enzyme is an interlocked homodimer with a pseudocatenane structure. ${ }^{26}$ The peptide $\alpha$-N-methyltransferase domains of the two subunits form a "back to back" interface while the clasp domain of one protomer wraps around the "front" of the methyltransferase domain of the other protomer.

Received: March 31, 2020

Accepted: June 3, 2020

Published: June 3, 2020 


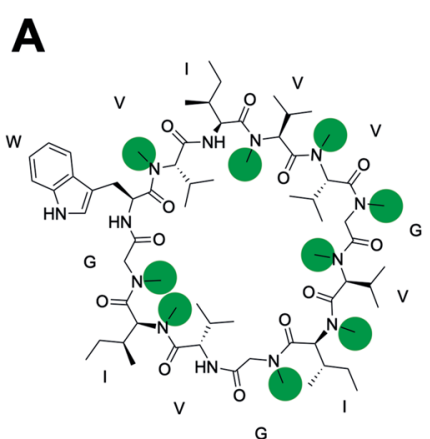

C

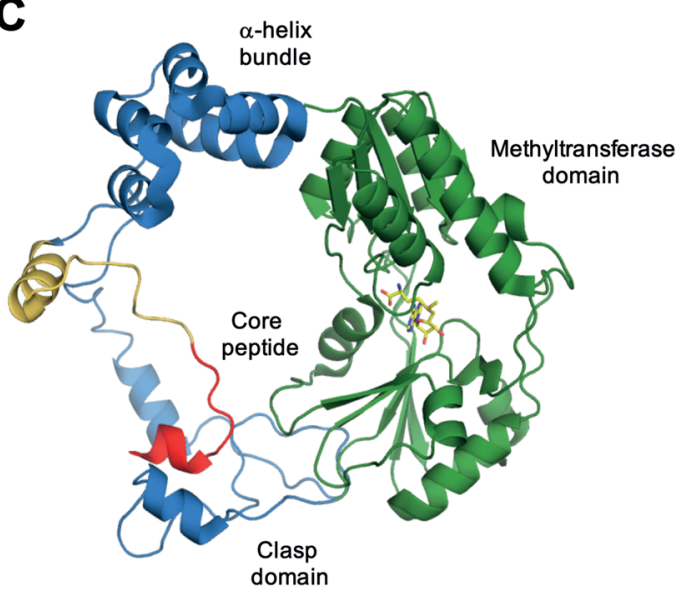

B

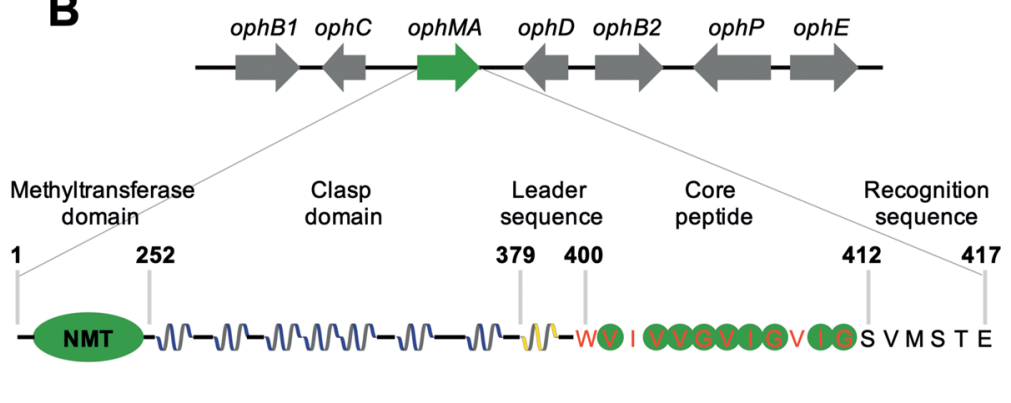

D

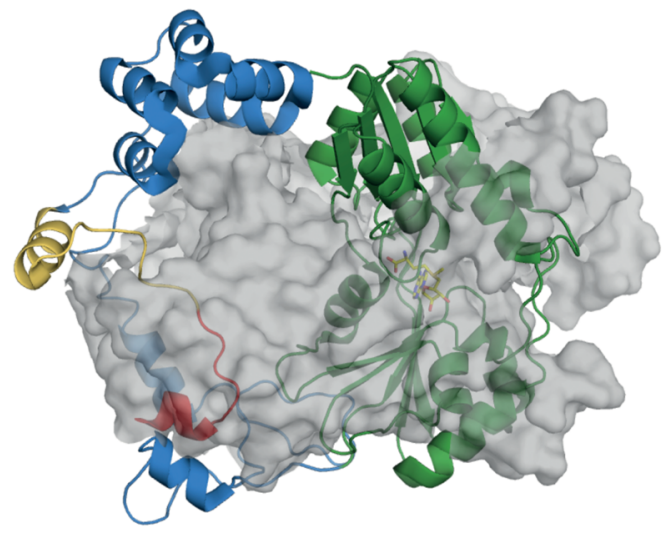

Figure 1. Overview of omphalotin biosynthesis. (A) Structure of omphalotin A, with methyl groups highlighted in green. (B) The putative biosynthetic gene cluster for omphalotin A. For OphMA, the methyltransferase domain is shown as a green sphere and the $\alpha$-helices of the clasp domain are shown in blue, respectively. The residues of the core peptide are colored in red. Methylated residues in the core peptide and the Cterminal recognition sequence are marked with green circles. (C) Monomer of OphMA 0 C6-Y98A (PDB ID: 5N0S) lacks the C-terminal recognition sequence; the methyltransferase domain is green, the clasp domain is blue, the leader sequence is yellow, and the core peptide is red. (D) Dimer of OphMA $\triangle$ C6-Y98A where the second subunit is represented in transparent surface (cyan). SAM is represented by sticks.

The substrate peptide from one protomer is modified at the active site of the other protomer (Figure 1C). ${ }^{26}$ The low reactivity of the amide bond is overcome through a combination of proton shuttling, conformation control, and steric clash between SAM and an amide proton in the active site. ${ }^{26,27}$ The core peptide is methylated in a distinct pattern, where, for example, Ile402 is not methylated (skipped) while Ile407 and Ile412 are methylated (see Figures 1A and 1B). A similar skipping occurs at Val409, while Val401, 403, 404, and 406 are methylated. The basis of this methylation pattern, which is conserved in two OphMA homologues ( $d b$ OphMA from Dendrothele bispora and LedMA from Lentinula edodes), ${ }^{24,25,27,28}$ has not been addressed.

One limitation on exploitation of OphMA in the biotechnological production of $N$-methylated macrocycles is the rather narrow known substrate profile (small hydrophobic residues, e.g., Ala and $\mathrm{Val}$ ). We show that the enzyme has a broader profile and is able to methylate also large hydrophobic, small polar, and even charged amino acids. We also demonstrate that some mutations of the core peptide profoundly alter the pattern of methylation, including residues that act as a stop and alternative start signals. Using structural analysis of the respective OphMA variants, we have been able to rationalize some of the rules governing the regioselectivity of the enzyme.

\section{RESULTS}

Core Peptide Substitutions Affect the Degree of Methylation. Small hydrophobic residues (Val, Ile) at positions 403, 404, 406, and 407 (Figure 1b) of the precursor protein were mutated to Thr, Glu, Arg, Phe, or Pro to probe effects of charge, size, and conformational rigidity. The mutations were introduced in the context of the full-length (including the C-terminal recognition sequence), N-terminally His-tagged protein (see Figure 1).

Mutant protein expression was induced in E. coli BL21(DE3) for $72 \mathrm{~h}$, and the degree of methylation was determined as described previously. ${ }^{24}$ The mutant and wild-type proteins eluted with the same retention time on a size exclusion column consistent with a folded dimeric state. The most abundant species of the wild-type protein showed complete methylation of the core peptide (9-fold) with an additional methylation at Val413 (Figure 2A). ${ }^{24}$ LC-ESI-MS extracted ion chromatograms (EIC) of proteolytic digests of the OphMA variants were analyzed to identify the most abundant methylated species for each variant (Figure 2). The number of methylations of the most abundant species (judged by integrated peak intensity) in each mutant was compared to the native to judge methylation efficiency.

The introduction of Thr at positions 403 and 404 resulted in similar methylation to wild-type (10-fold methylated species most abundant) (Figure 2A and 2B). In I407T, methylation was slightly reduced (9-fold). However, the introduction of Thr at position 406 reduced methylation, with a 3-fold 

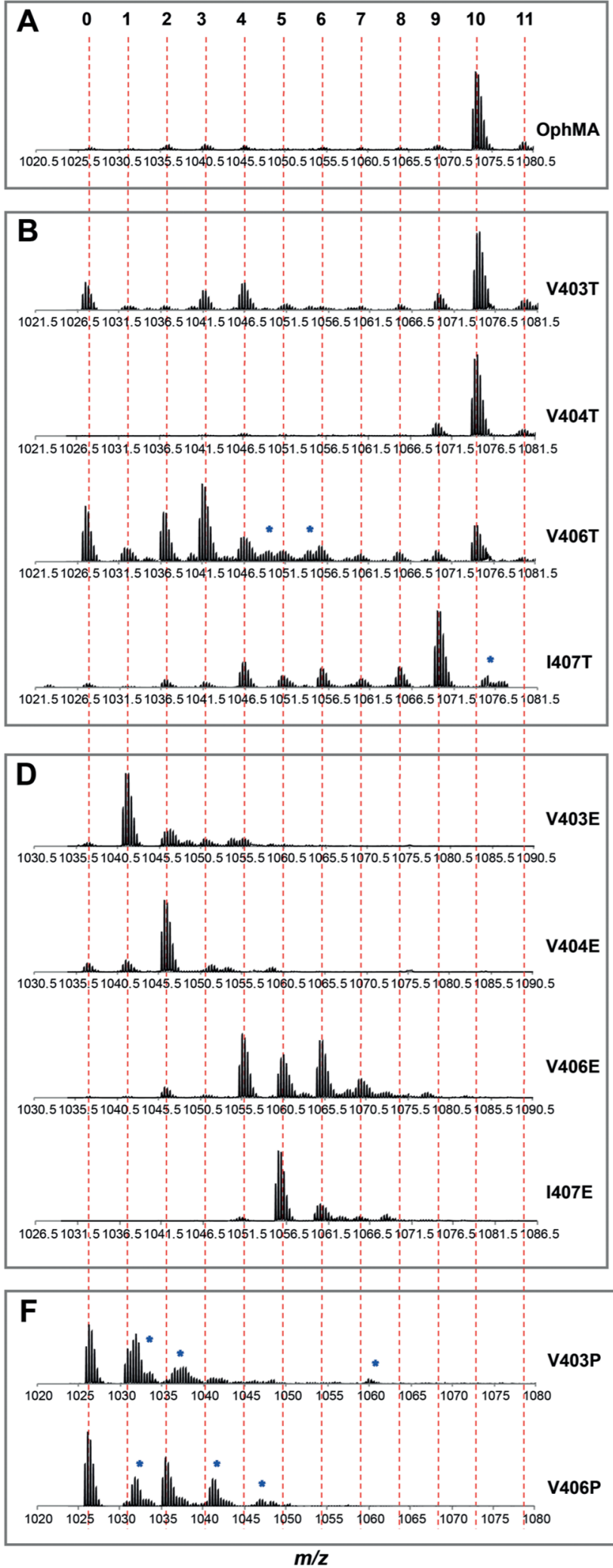
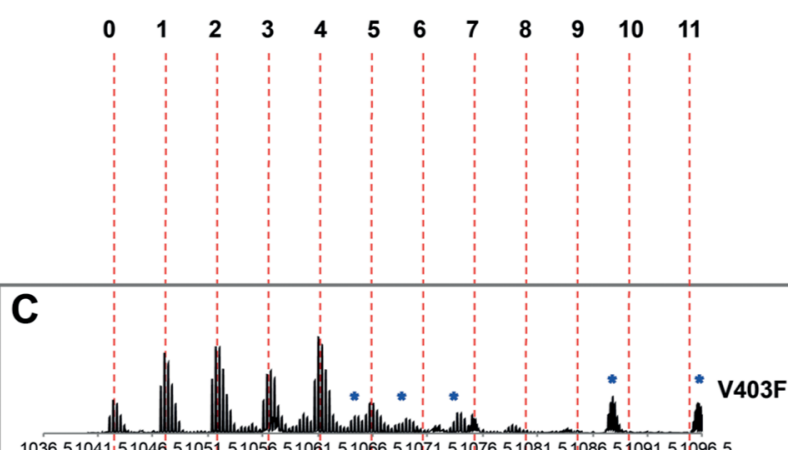

1036.51041 151046.51051.51056.51061.51066.51071.51076.51081.51086.51091.51096.5

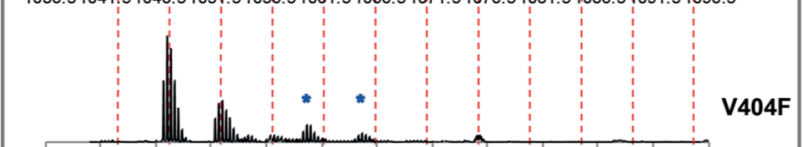

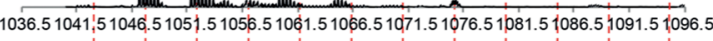

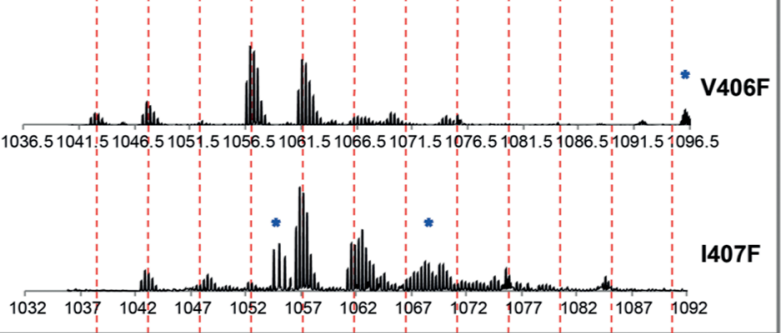

$\mathbf{E}$

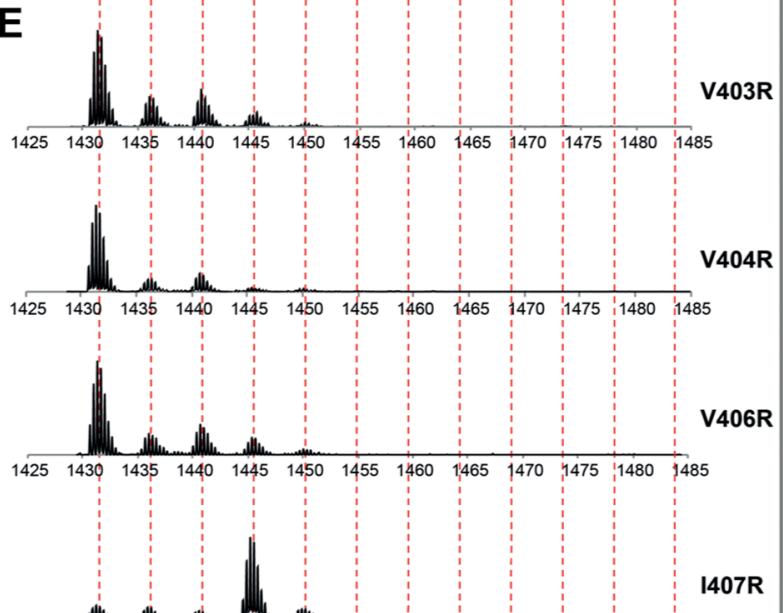

$1420.51425 ! 51430.51435 .51440 .51445 .51450 .51455 .51460 .51465 .51470 .51475 .51480 .5$

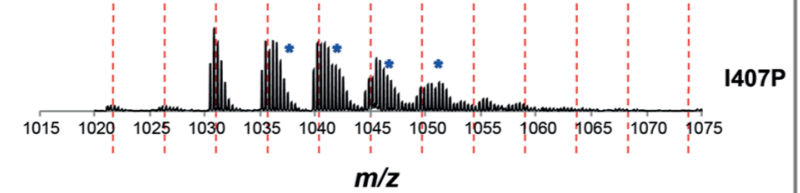

$m / \mathbf{z}$

Figure 2. Methylation analysis of full-length OphMA core peptide variants under in vivo conditions. LC-ESI-MS analysis of methylation of (A) OphMA wild type; (B) OphMA V403T, V404T, V406T, and I407T; (C) OphMA V403F, V404F, V406F, and I407F; (D) OphMA V403E, V404E, V406E, and I407E; (E) OphMA V403R, V404R, V406R, and I407R; and (F) OphMA V403P, V406P, and I407P. Red dashed lines mark the number of methylations states. Co-eluting contaminants are marked with a blue asterisk. The integrated peak intensity was used to estimate the relative abundance of the peptide species.

methylated species being the most abundant (Figure 2B). The introduction of the large hydrophobic Phe generally decreased methylation but the effect was dependent on the position (Figure 2C). Substitution at position 403 yielded comparably 
A ophma WVI RVGVIGVIGS VMSTE

B V403T WVI PVGVIG V IG S VM S T E V404T WV I VCGVDG V DG S VM S T E V406T WV I VVG T I G V I G S VMSTE 1407T WV I VVGVOG V I G S VM S TE

C V403F WVOPG I G V I G S M T T V404F W V I V F G I G I G S V M S T E V406F W VIV V G F I G V I G S V M S T E 1407F W V I V V G V F G V I G S V M S TE
V403T WVDOVGVDG V I G S V M S T E V404T WV I VOGVDG V I G S VMS T E V406T WV I VVGOTG V I G S VM S T E 1407T WV I VVGVOG V I G S V M S T E V404F WV I VF G I G V I G S VM S T E V406F WV I VVGF I GV I G S V M T E 1407F WVOVVG V F G V I G S V M S T E $W V$ I VVGVOG V I G S V M TE

D V403E WVI E V G V I G V I G S V M S T E V403E V404E WV I VE G V I G V I G S V M S T E V404E

V406E WV I VVG E I G V I G S V M S T E V406E I407E W V I VVGVE G V I G S V M S T E

E V403R WV I R V G V I G V I G S VM S T E V404R WV I VR G V I G V I G S V M S T E $W \vee I V R G \vee I G \vee I G S \vee M S T E$ V406R WV I V V G R I G V I G S V M S T E $W \vee I V \vee G R I G \vee I G S \vee M S T E$

1407R W V I VV G V R G V I G S V M S T E
WVDCVGVI G V I G S M T T $W V I V O G V I G \vee I G S V M S T E$ WVDVOGVIGVIGSVMSTE WVDVVGE I G V I GS VMSTE WV I VVGE I G V I GS VMS TE 1407E WV I VVGVOG V I G S VM S T E

V403R W V I R V G V I G V I G S V M S T E V404R WV I VR G V I G V I G S M S T E

V406R WV I VVGR I G V I G S V M S T E $W \vee I V \vee G R$ I G V I GSVMSTE WVIVVGR I GV I GSVMSTE 1407R WV I VVGVR G V I G S V M S T E WV I VVGVR G I G S V M T E

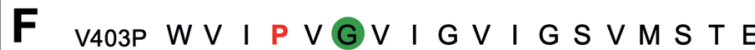
$W \vee$ I P V G I I G V I G S VMSTE V406P WV I V V G P I G V I G S V M S T E

V403P

WVI PVGVIGVIGSVMSTE $W V$ I PVGVIGVIGSVMSTE V406P WV I VVG P I G V I G S VM S T E WVDVVGP I G V I GS VMSTE WVIVVGP I G V I GSVMSTE 1407P WV I V V G V P G V I G S V M S T E I407P WV I VVGV P G V I G S V M S T E

Figure 3. Methylation pattern analysis of full-length OphMA core peptide variants under in vivo conditions. Peptides detected by LC-ESI-MS were further analyzed by HPLC-ESI-MS/MS. The most abundant (left) and most methylated (right) species are shown. For some species, more than one isoform was detected. In these cases, all detected isoforms are listed. Wild-type OphMA is shown in panel (A); Thr substitutions are shown in panel (B); Phe substitutions are shown in panel (C); Glu substitutions are shown in panel (D); Arg substitutions are shown in panel (E); and Pro substitutions are shown in panel (F). Substitutions are shown in red. Solid green circles indicate methylated residues confirmed by MS/MS, while solid yellow circles are assumed to be based on the number and pattern of methylation but they are not experimentally confirmed by MS/MS.

abundant monomethylated, dimethylated, trimethylated, and tetramethylated species, while V404F yielded mainly monomethylated peptides. A tetramethylated species and, to a lesser extent, a trimethylated species, resulted from a V406F substitution, while the I407F mutant yielded mainly a tetramethylated species with some pentamethylated species (Figure 2C). Introduction of Glu also decreased the degree of methylation in a position-dependent manner. Substitutions at positions 403, 404, and 407 yielded peptides with 1, 2, and 5 methylations, respectively (Figure 2D). Substitution at position 406 produced a mixture of similarly abundant peptides containing 4, 5, or 6 methylations (Figure 2D). Introduction of the large and positively charged Arg residue strongly decreased the degree of methylation, irrespective of its position (Figure 2E). At position 407, the dominant species carried three methylations (Figure 2E). At positions 403, 404, and 406, the dominant species was unmethylated, with the next most abundant having two methylations (Figure 2E). Proline was introduced at positions 403, 406, and 407 (Figure 2F). In both V403P and V406P, the dominant species was unmethylated, but V403P showed evidence for two methylations, while V406P showed evidence for two and four methylations (see Figures $2 \mathrm{~F}$ and Figure 3F, as well as Figure S1f4 in the Supporting Information). The I407P variant had a variety of species (two to four methylations) (Figure 2F), with evidence of up to six methylations (see Figure 3F, as well as Figure S1f6 in the Supporting Information). 

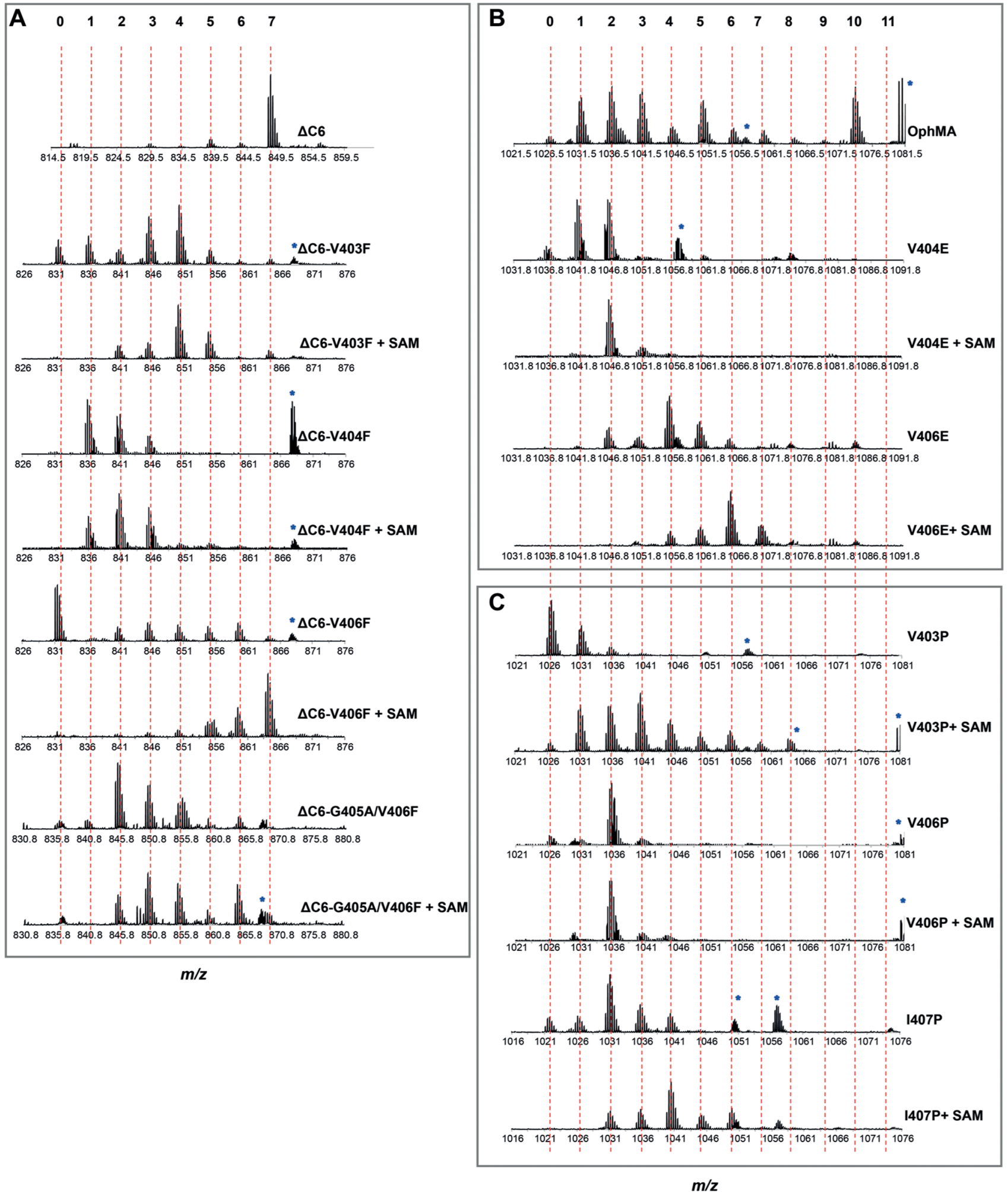

Figure 4. Methylation analysis of selected $\triangle \mathrm{C} 6$ and full-length OphMA core peptide variants after in vitro SAM incubation. LC-ESI-MS was used to measure the extent and estimate the relative abundance of methylated species: (A) selected OphMA $\Delta$ C6 Phe-substitutions, (B) selected fulllength OphMA Glu-substitutions, and (C) selected full-length OphMA Pro-substitutions. Contaminants are marked with a blue asterisk.

Core Peptide Substitutions Alter the Pattern of Methylation. The patterns of methylation of both the most abundant and highly methylated species were analyzed by HPLC-ESI-MS/MS (see Figure S1 in the Supporting Information), and the results are summarized schematically in Figure 3.
Thr substitutions at 403, 404, and 407 showed a wild-type methylation pattern from Val401 to Val413 (skipping Ile402, Val409, and Ser412) (see Figure 3B, as well as Figure S1). In V406T, methylation terminated at position 404 but was wildtype to this point (see Figure 3B, as well as Figures S1b5 and S1b6 in the Supporting Information). 


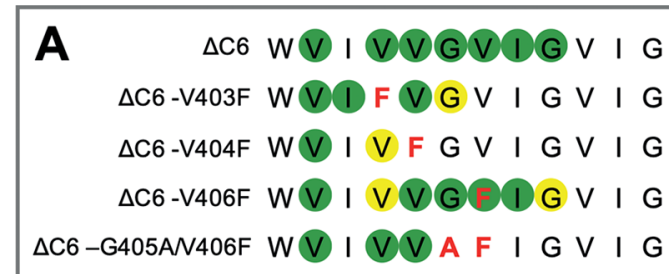

\section{$\triangle c 6-V 403 F \quad W V$ I $\odot$ VGVIG V I G \\ $\triangle C 6-V 404 F \quad W V$ I VOGV I G V I G \\ $\triangle C 6-V 406 F \quad W V$ I $V \vee G O D G \vee I G$ \\ $\triangle C 6-G 405 A N 406 F$ W I VVOOCG I G}

\section{B OphMA WV I VVGVDG V I G S S T E \\ V404E WV I VE G V I G V I G S V M S T E V406E WV I VVGE I G V I G S VM S T E}

V404E WV I VOG V I G V I G S V M S T E V406E WVPVVG I G V I GS VM S T E

$\begin{aligned} & \text { C } \text { V403P W V I P V G V I G V I G S V M S T E } \\ & \text { V406P WV I V V G P I G V I G S V M S T E } \\ & \text { L407PWV I VVGV P G V I G S V M S T E }\end{aligned}$
V403P WV I P VGV I G V I G S VM S T E
V406P WV I VVG P I G V I G S V M S T E
1407P WV I VVGV P G V I G S VM S T E

Position of N-Met confirmed by MS/MS

MS/MS-detected but undefined N-Met position

Figure 5. Methylation pattern for core peptide mutants of OphMA or $\triangle \mathrm{C} 6$ after in vitro SAM incubation. The methylation pattern of the most abundant (left side) and most methylated (right side) species: (A) OphMA $\Delta$ C6-variants V403F, V404F, V406F, and G405A/V406F; (B) OphMA-variants V404E and V406E; (C) OphMA-variants V403P, V406P, and I407P. Color coding is as described in Figure 3.

In contrast, the introduction of Phe resulted in a significantly altered methylation pattern. V403F, V406F, and I407F mutants showed a pattern where Ile 402 was, in contrast to the wild-type situation, methylated (see Figure 3C, as well as Figures S1c2, S1c4, and S1c6 in the Supporting Information). The introduction of Phe terminated methylation in most mutants either one or two residue $\mathrm{N}$-terminals to the Phe (see Figures 2C and 3C, as well as Figures S1c1, S1c3, S1c5, and S1c7 in the Supporting Information).

Examination of the most abundant peptides in the Glu mutants revealed that, generally, methylation ended immediately prior to the Glu residue (with a wild-type methylation pattern; see Figure 3D, as well as Figures S1d1-S1d8 in the Supporting Information). Analysis of the most highly methylated species revealed that methylation of Phe and Glu residues by OphMA was possible (see Figures $2 \mathrm{C}$ and 2D, and Figures $3 \mathrm{C}$ and $3 \mathrm{D}$ ).

The presence of Arg terminated methylation prior to the Arg (see Figure 3E, as well as Figures S1e3, S1e4, S1e7, and S1e8 in the Supporting Information). Arg itself was not methylated by OphMA. Analysis of the doubly methylated peptides isolated from V403R, V404R, and V406R showed methylation C-terminal to Arg with a profoundly disrupted methylation pattern (see Figure 3E, as well as Figures S1e1, 2S1e, S1e5, and S1e6 in the Supporting Information). Pro, which cannot be methylated, appeared able to function as an alternate start (V403P) or as a stop (V406P, I407P) signal for methylation, depending on its location (see Figures $2 \mathrm{~F}$ and $3 \mathrm{~F}$, as well as Figures S1f1-S1f6 in the Supporting Information).

In vitro Methylation Analysis for OphMA Variants. Previous work showed that partially methylated OphMA active site mutants can be purified from E. coli and further methylated in vitro upon incubation with SAM. $^{26}$ We applied this procedure to the mutants where methylation appeared to be halted (stalling mutants), V404E, V406E, V403P, V406P, I407P, $\Delta$ C6-V403F, $\Delta$ C6-V404F, and $\Delta$ C6-V406F, as well as the double mutant $\Delta$ C6-G405A/V406F. The prefix abbreviation $\Delta \mathrm{C} 6$ denotes the deletion of residues $412-417$, yielding a protein that is easier to crystallize and characterize than the full-length protein but is a valid model for the full-length protein. $^{26}$ The most abundant C-terminal peptide of OphMA $\Delta$ C6 is 7 -fold methylated, with a pattern identical to the wild-type protein (see Figures 4 and 5).

After $20 \mathrm{~h}$ of induction in E. coli, most (with $71 \%$ relative abundance) of OphMA $\Delta$ C6 was already completely (7-fold) methylated (see Figure 4A and Table 1). ${ }^{26}$ Full-length OphMA was not completely methylated under these conditions, but the relative abundance of the 10 -fold methylated species was

Table 1. Percentage of the Three Most Abundant Methylated Species of Selected OphMA Variants Used in the In Vitro Assays ${ }^{a}$

\begin{tabular}{lcll}
\multicolumn{1}{c}{ OphMA variant } & $\begin{array}{c}\text { most abundant } \\
\text { species (a. sp. }\end{array}$ & second a. sp. & third a. sp. \\
$\Delta$ C6 & $7 \mathrm{Me}, 71 \%$ & $5 \mathrm{Me}, 10 \%$ & $6 \mathrm{Me}, 7 \%$ \\
$\Delta$ C6-V403F & $4 \mathrm{Me}, 30 \%$ & $3 \mathrm{Me}, 19 \%$ & $1 \mathrm{Me}, 16 \%$ \\
$\Delta$ C6-V403F + SAM & $4 \mathrm{Me}, 44 \%$ & $3 \mathrm{Me}, 20 \%$ & $5 \mathrm{Me}, 14 \%$ \\
$\Delta$ C6-V404F & $2 \mathrm{Me}, 45 \%$ & $3 \mathrm{Me}, 24 \%$ & $1 \mathrm{Me}, 23 \%$ \\
$\Delta$ C6-V404F + SAM & $2 \mathrm{Me}, 41 \%$ & $3 \mathrm{Me}, 26 \%$ & $1 \mathrm{Me}, 22 \%$ \\
$\Delta$ C6-V406F & $0 \mathrm{Me}, 54 \%$ & $6 \mathrm{Me}, 10 \%$ & $3 \mathrm{Me}, 10 \%$ \\
$\Delta$ C6-V406F + SAM & $7 \mathrm{Me}, 41 \%$ & $6 \mathrm{Me}, 23 \%$ & $5 \mathrm{Me}, 15 \%$ \\
$\Delta$ C6-G405A/V406F & $2 \mathrm{Me}, 31 \%$ & $3 \mathrm{Me}, 30 \%$ & $4 \mathrm{Me}, 17 \%$ \\
$\Delta$ C6-G405A/V406F & $3 \mathrm{Me}, 30 \%$ & $4 \mathrm{Me}, 20 \%$ & $6 \mathrm{Me}, 19 \%$ \\
+ SAM & $3 \mathrm{Me}, 23 \%$ & $10 \mathrm{Me}, 20 \%$ & $5 \mathrm{Me}, 20 \%$ \\
OphMA & $2 \mathrm{Me}, 57 \%$ & $1 \mathrm{Me}, 25 \%$ & $0 \mathrm{Me}, 10 \%$ \\
V404E & $2 \mathrm{Me}, 74 \%$ & $3 \mathrm{Me}, 12 \%$ & $1 \mathrm{Me}, 7 \%$ \\
V404E + SAM & $4 \mathrm{Me}, 44 \%$ & $5 \mathrm{Me}, 22 \%$ & $3 \mathrm{Me}, 10 \%$ \\
V406E & $6 \mathrm{Me}, 44 \%$, & $5 \mathrm{Me}, 20 \%$ & $7 \mathrm{Me}, 16 \%$ \\
V406E + SAM & $0 \mathrm{Me}, 47 \%$ & $1 \mathrm{Me}, 31 \%$ & $2 \mathrm{Me}, 12 \%$ \\
V403P & $3 \mathrm{Me}, 19 \%$ & $2 \mathrm{Me}, 17 \%$ & $1 \mathrm{Me}, 17 \%$ \\
V403P + SAM & $2 \mathrm{Me}, 69 \%$ & $0 \mathrm{Me}, 13 \%$ & $1 \mathrm{Me}, 10 \%$ \\
V406P & $2 \mathrm{Me}, 78 \%$ & $3 \mathrm{Me}, 5 \%$ & $1 \mathrm{Me}, 5 \%$ \\
V406P + SAM & $2 \mathrm{Me}, 32 \%$ & $1 \mathrm{Me}, 21 \%$ & $3 \mathrm{Me}, 19 \%$ \\
I407P & $4 \mathrm{Me}, 36 \%$ & $3 \mathrm{Me}, 17 \%$ & $2 \mathrm{Me}, 16 \%$ \\
I407P + SAM & & & \\
& & &
\end{tabular}

${ }^{a}$ The relative abundance is determined by integrating the EIC peaks and calculating the ratio between the integration of a specific species and the sum of the integrations of all species. 

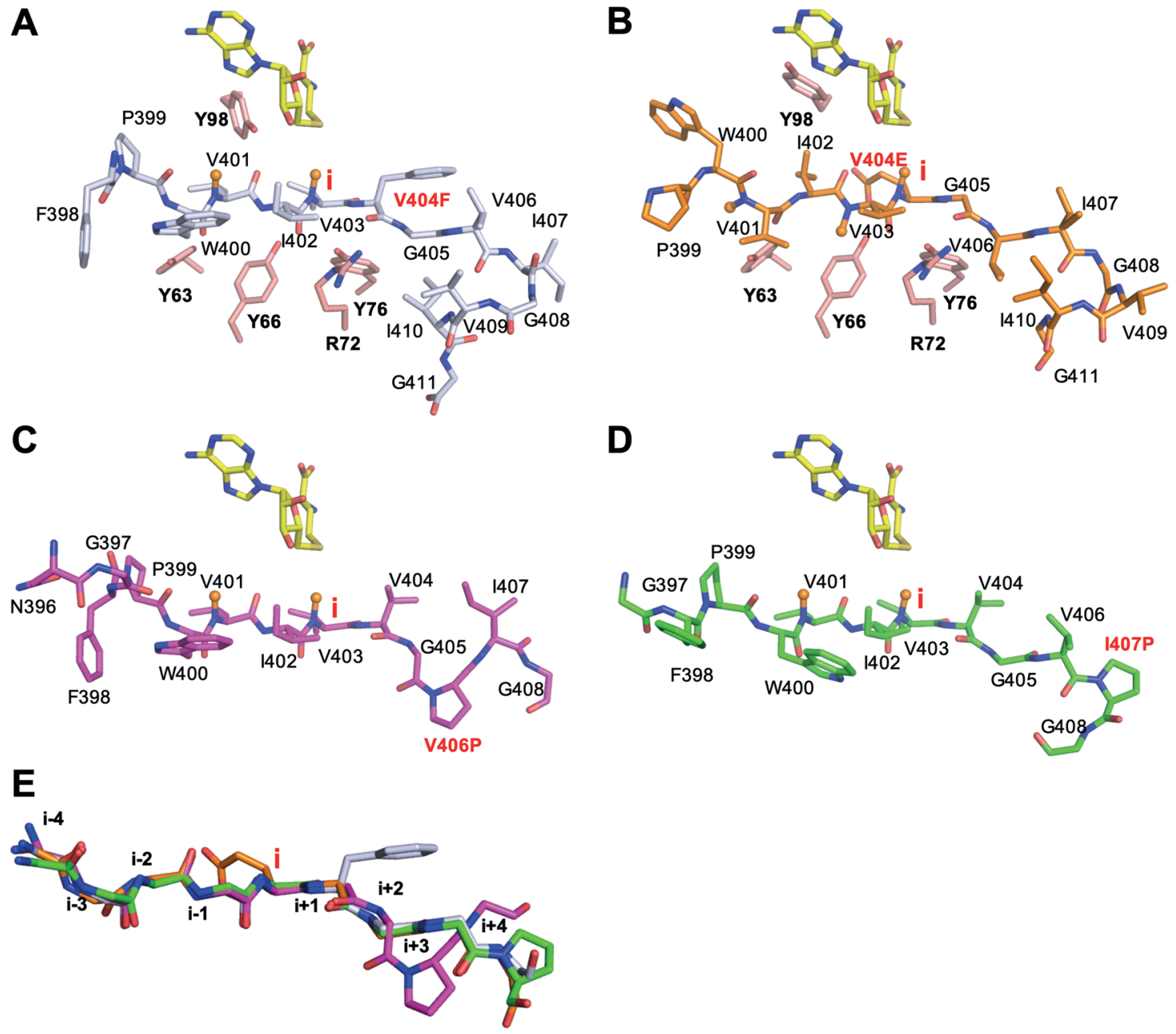

Figure 6. Active site view of several "stalling" mutants: (A) OphMA $\Delta$ C6-V404F has Phe404 at $i+1$ position; (B) OphMA-V404E has Glu404 at position $i$ and a different conformation of Tyr98; (C) OphMA-V406P has a cis-peptide conformation; (D) OphMA-I407P has a trans-peptide conformation; and (E) superimposition of OphMA-V406P (purple), OphMA-V404E (orange), OphAMA $\Delta$ C6-V404F (silver), OphMA-I407P (green), and, for comparison, OphMA-Y63F (cyan, PDB ID: 5N0N, ${ }^{26}$ methylated V403 at position $i$ ).

already significant (see Figure 4B and Table 1). OphMA $\Delta$ C6V403F was mostly 4-fold methylated, similar to the in vivo results for the full-length OphMA V403F variant. Incubation of this protein with SAM for three days resulted in a shift to more methylated species with evidence of methylation of Phe403 (see Figures 4A and 5A, as well as Figures S2a and S2b in the Supporting Information). In contrast, the $\Delta$ C6-V404F variant was purified as monomethylated, dimethylated, and trimethylated species whose distribution changed little upon incubation with SAM. Compared to the full-length V404F variant, the truncated protein revealed a higher degree of methylation (Figure 4A), with clear evidence that Phe404 was methylated (Figure S2d in the Supporting Information). OphMA $\Delta$ C6V406F purified with the unmethylated species being dominant but upon incubation with SAM became completely (7-fold) methylated (Figure 4A). The methylation pattern of this species was the same as that for wild-type OphMA $\Delta$ C6 and Phe406 was methylated (see Figure 5A, as well as Figure S2e in the Supporting Information). The double mutant $\Delta$ C6G405A/V406F yielded a range of methylated species (see Figure $5 \mathrm{~A}$, as well as Figure $\mathrm{S} 2 \mathrm{~g}$ in the Supporting Information), with the 2 -fold methylated species being most abundant (Figure 4A). Only a limited increase in methylation occurred upon incubation with SAM (Figure 4A).
The full-length OphMA-V404E variant was purified as a mixture of monomethylated and dimethylated species (with methylation at Val401 and Val403) from E. coli (see Figure 4B, as well as Figure $\mathrm{S} 2 \mathrm{~h}$ in the Supporting Information), consistent with the in vivo data. Incubation with SAM resulted in accumulation of a dimethylated species and proteins with additional methylations at Glu404, Gly411, and Val413 (see Figure 4B, as well as Figure S2 $\mathrm{i}$ in the Supporting Information). OphMA-V406E purified as a mixture of species (Figure $4 \mathrm{~B}$ ), such as the in vivo analysis. Incubation with SAM yielded a 6-fold methylated species but residues 406 to 410 were skipped (Figure 5B). An 8-fold methylated species was detected, suggesting the methylation of Ile402 and Val409 (see Figure $5 B$, as well as Figure $S 2 k$ in the Supporting Information).

OphMA-V403P was purified mostly as unmethylated protein with some monomethylated and dimethylated species (Figure 4C). Upon incubation with SAM, further methylation up to a maximum of 7 -fold was observed (Figure 4C). MS/MSanalysis suggested that methylation occurred at a variety of positions but only after the introduced Pro residue (see Figure $5 \mathrm{C}$, as well as Figure $\mathrm{S} 2 \mathrm{~m}$ in the Supporting Information). OphMA-V406P was purified as dimethylated species (Val401 and Val403), with evidence for a very small amount of Val404 
methylation upon incubation with SAM (see Figures 4C and $5 \mathrm{C}$, as well as Figures $\mathrm{S} 2 \mathrm{n}$ and $\mathrm{S} 2 \mathrm{o}$ in the Supporting Information). Similar to the in vivo analysis, OphMA-I407P was a mixture of monomethylated, dimethylated, trimethylated, and tetramethylated species (Val401, Val403, Gly404, and Val405) (see Figures 4C and 5C, as well as Figure S2p). Incubation with SAM resulted in a decrease of the dimethylated and a concomitant increase in the tetramethylated species (Figure 4C). MS/MS analysis revealed 5- and 6fold methylated species (at Gly411 and Val413; see Figure 5C, as well as Figure $\mathrm{S} 2 \mathrm{q}$ in the Supporting Information). Our results differ from $d b$ OphMA, where I407P abolished methylation and V403P yielded a single methylation. ${ }^{27}$

Structural Analysis of Some OphMA Core Peptide Variants. The crystal structures of OphMA-V404E, OphMA $\Delta$ C6-V404F, OphMA-V406P, and OphMA-I407P in complex with SAH were determined at resolutions of 1.9, $1.8,1.6$, and $2.2 \AA$, respectively (Table S1). The overall structures of the four mutants are unchanged from OphMA $\Delta$ C6-SAH (PDB ID: 5N0Q). ${ }^{26}$

The structure of V404F showed the clear electron density for SAH, methylation at Val401, and methylated Val403 at the active site (denoted as position $i$, following the previous nomenclature $^{26}$ ) (see Figure 6A, as well as Figure S3 in the Supporting Information). The backbone of C-terminal substrate peptide and the active site residues overlap well with active site mutant OphMA-Y63F, with a root-meansquare deviation (rmsd) of $0.76 \AA$ (PDB ID: $5 N_{0 N}^{26}$ ) (Figure $6 \mathrm{E}$ ). Phe 404 sits at $i+1$ and interacts with many of the active site residues but does not significantly perturb their arrangement. In the V404E structure, the electron density of chain B was clear and modeled as a trimethylated species with methylated Glu404 at position $i$ and SAH bound at the active site (see Figure 6B, as well as Figure S3). The conformation of the introduced Glu404 requires Tyr98 to adopt a conformation that was not observed previously and would seem "inactive" (see Figure 6B, as well as Figure S4 in the Supporting Information). In chain A, the electron density of the substrate peptide was heterogeneous, ${ }^{26}$ and our best model has methylated Val401 (monomethylated species) at position $i$ with SAH bound to the protein. Heterogeneity in the electron density has been suggested ${ }^{26}$ to arise from heterogeneity of methylation in the protein and may be unavoidable for some samples, such as V404E (see Figures 4B and 5B).

The structure of V406P shows the clear electron density for Asn396 to Gly408 with Val401 and Val403 methylated (Figure $\mathrm{S} 3 \mathrm{~b})$, consistent with in vitro analysis (Figure 4D). The substrate peptide adopts the same conformation as that seen in the native structure ${ }^{26}$ until it reaches Val404. The introduction of the Pro residue has resulted in a cis-peptide bond between Gly405 and V406P (positions $i+2$ and $i+3$ ) (Figures 6C and $6 \mathrm{E})$, which prevents further substrate translocation. The structure of I407P shows a well-resolved C-terminal peptide from Gly397 to Gly408 with clear density for methylated Val401 and Val403 (position (i). I407P at position $i+4$ has a normal trans-peptide conformation (see Figure 6D).

\section{DISCUSSION}

Methylation of peptide amide $\mathrm{N}$ atoms is desirable but chemically challenging. The enzyme OphMA is unusual in that the $\alpha$-N-methyltransferase domain and its substrate (core peptide) are part of the same polypeptide. The catalytic domain of the enzyme binds the core peptide and a SAM molecule in a hydrophobic tunnel that is formed by the dimeric arrangement of two OphMA molecules. For omphalotin biosynthesis, the core peptide is cleaved out and macrocyclized by the prolyloligopeptidase OphP; the remainder of the enzyme is assumed to be discarded. ${ }^{24}$ The covalent attachment of the substrate to the enzyme renders the otherwise very hydrophobic (and insoluble) substrate soluble and increases its local concentration and, hence, the rate of the reaction. The side chains of the core peptide are not recognized by the enzyme ${ }^{26}$ and, thus, the covalent linkage may also compensate for the lack of recognition. Despite this apparent lack of recognition, there is a distinct methylation pattern (skipping of some residues), but what underpins this is unknown.

Sequence alignments of fungal OphMA homologues show that the core peptide sequences are biased toward hydrophobic (Gly, Ile, Val, Leu) and small hydrophilic (Thr) amino acids. ${ }^{28}$ Since evolution would be expected to select for the properties of the compound, the enzymes may be naturally promiscuous, allowing mutations of the core sequence without requiring compensating mutations in the catalytic machinery. Substrate plasticity has previously been investigated by replacing the entire core peptide with unrelated sequences of other backbone $N$-methylated peptide natural products. This showed that OphMA was able to methylate residues in these other sequences but with patterns different from either omphalotin or the desired natural product. ${ }^{24}$ Here, we report a systematic analysis of single substitutions at different positions of the core peptide by small hydrophilic (Thr), large charged (Arg or Glu), large hydrophobic (Phe), and conformationally rigid (Pro) residues. Threonine was well-tolerated at all positions, although the degree of methylation was slightly lower than wild-type. We attribute this slight decrease in the methylation efficiency to the mismatch between the hydrophobic tunnel and the hydrophilic side-chain hydroxyl of threonine. Consistent with our results, the homologue $d b O$ phMA natively methylates a threonine residue. ${ }^{24,25,27}$ The introduction of Arg effectively abolishes methylation, except in one variant, I407R, where three residues N-terminal to Arg were efficiently methylated before halting at Val404. The large positively charged residue is likely to be incompatible with the hydrophobic substrate tunnel.

Glu does not have such a pronounced effect as Arg, and methylation proceeds up to the position of the introduced Glu, where it stalls. The stalling is not absolute and the enzyme can methylate Glu albeit slowly and we detect peptides with methylation C-terminal to the introduced Glu (see Figures 2D, $3 \mathrm{D}, 4 \mathrm{~B}$, and $5 \mathrm{~B}$ ), suggesting Glu can translocate through the active site. The crystal structure of SAH-bound OphMAV404E, which has a methylated Glu at the active site, reveals that catalytically essential residue Tyr $98^{26}$ adopts an "inactive" conformation to accommodate Glu. We hypothesize that this distortion of the active site is responsible for the very slow methylation rate (stalling).

The presence of phenylalanine altered both the pattern and degree of methylation ( $\mathrm{N}$-terminal and $\mathrm{C}$-terminal to site of mutation) but its effect was highly dependent on its position. Simple modeling shows that the larger phenylalanine side chain requires a rearrangement of the core peptide and/or the enzyme to avoid severe van der Waals clashes when Phe occupies either the $i-1, i$, or $i+2$ positions. Since methylation was observed, these changes must be possible, but we suggest they cause multiple stalling events. The clashes at the $i+2$ site 
explain the observed stalling of methylation two residues before the Phe in three such variants (see Figures $2 \mathrm{C}$ and $4 \mathrm{~A}$ ). In the V403F mutant, Phe would occupy the $i+2$ position as this is the starting configuration for the protein; its subsequent translocation to $i+1$ would reduce clashes but further translocation to position $i$ would be disfavored (second stalling event). We propose, with Phe stalling further translocation, that Ile402 is held at position $i$ and methylated (rather than skipped). Finally, modeling suggests that there is potential for $\pi$-stacking between a Phe at the $i-2$ position and Tyr63, giving rise to third stalling event, but arising from preserving favorable interactions rather than avoiding clashes. This event would explain the pattern observed for OphMA variants V403F and V404F where methylation apparently stalled two residues after the introduced Phe.

Proline cannot be a substrate for the enzyme and would cause extensive steric clashes at the active site. The introduction of proline at position 403 of OphMA completely eliminates methylation. Prolonged incubation with SAM yields some methylation but starting after Pro403 and with heterogeneous patterns suggestive of multiple start sites. We suggest that this arises as a result of the Pro inducing conformations in the substrate that mimic (imperfectly) the natural start site after Pro399 and consequent "misfolding" of some protein. Proline introduced at either residue 406 or 407 gives rise to wild-type methylation which stops at Val403 or Gly405, respectively. Structural analysis of the V406P mutant reveals that the proline adopts a cis-peptide conformation with Gly405 which acts as a stop signal at $n-2$ to the proline. I407P shows that the proline adopts a trans conformation, which acts as a stop signal, but at $n-1$ relative to the proline. The small amount of methylation at Val404 in V406P could arise from a small amount of trans-configured peptide. ${ }^{29,30}$

Unexpectedly, the enzyme is able to process large residues such as Phe and the negatively charged Glu. In many cases, the heterogeneous methylation in vivo can be driven to completion by incubation in vitro with SAM. This inherent promiscuity of the enzyme indicates synthetic potential. However, the tolerance of the active site is not limitless (Arg cannot be processed and appears unable to enter the active site tunnel). Peptide flexibility appears to be important, because the V406F mutant (Phe follows Gly405) was methylated to a much higher degree than other Phe variants. The double variant G405A/ V406F, which reduced the flexibility, showed a reduced degree of methylation, compared to V406F (Figure 4A), which is consistent with this suggestion.

There are three Ile residues in the wild-type core peptide, two of which are methylated and one is skipped; thus, the methylation pattern is not a function of the nature of the residue. Our data provide evidence that the pattern arises from the translocation of the six residues of the substrate peptide that are in contact with the enzyme substrate tunnel during catalysis (positions $i-3$ to $i+2$ ). We suggest the analogy of a clutch as means to think of the methylation pattern. When the clutch is disengaged, the gears mesh and this is equivalent to peptide translocation and methylation. When the clutch is engaged, the gears rotate freely and this equivalent to skipping, where the peptide moves through the active site faster than it can be positioned for catalysis. In the V403F, Ile is stuck at the active site (the gears mesh) long enough for it to be methylated. In the Glu variants, the active site Try98 is displaced (gears rotate freely) and this results in extensive skipping before methylation can resume. In the same way, we suggest that distortion of the active site during Pro passage results in multiple skipping explaining the pattern of methylation C-terminal to Pro in I407P (see Figures 3F and 5C).

By introducing point mutations in the core peptide sequence of OphMA, we show that the substrate promiscuity of this peptide $\alpha-N$-methyltransferase is larger than anticipated from the naturally occurring core peptide sequences of fungal OphMA homologues. ${ }^{28}$ An additional challenge for biotechnological applications of OphMA, besides substrate promiscuity, is how to control the enzyme to produce a homogeneously methylated product. In this regard, we have been able to identify some of the factors and mechanisms controlling the efficiency and the pattern of OphMA-mediated peptide methylation. These insights will be useful for applications like the production of de novo libraries of multiply backbone $\mathrm{N}$ methylated peptides for the development of peptide therapeutics.

\section{MATERIALS AND METHODS}

Materials and General Procedures. Plasmid DNA purification from E. coli cultures was performed using the Nucleospin spin columns (Macherey-Nagel). DNA from PCR, restriction digests, and ligations was purified either first by agarose gel electrophoresis or spin columns. DNA concentration was determined spectrophotometrically using NanoDrop (Thermo Fisher Scientific). DNA manipulations were performed according to manufacturer recommendations or using standard procedures. ${ }^{32}$ DNA sequencing, synthesis, and purification by desalting of oligonucleotides was performed by Microsynth AG. Primers for full-length V406P, V404E, and OphMA $\Delta$ C6-V404F were purchased from IDT. Fast-digest restriction endonucleases, Phusion DNA-polymerase, and T4 DNA ligase were purchased from Thermo Scientific or New England Biolabs. Crystallization screens were purchased from Hampton Research and Molecular Dimensions. EDTA-free Protease Inhibitor Cocktail (cOmplete) were bought from Roche. Other chemicals were purchased from Sigma-Aldrich/Fluka.

Bacterial Strains and Plasmids. Escherichia coli strains DH5 $\alpha$ and BL21 (DE3) were used for cloning and protein production, respectively. Plasmids PMA997 (pET24-OphMA), PMA1004 (pET24-His8-OphMA), and PMA1304 (pET24-His8-OphMATEVcs- $\Delta$ C6) were described previously. ${ }^{24}$ Plasmids constructed in this study are listed in Table S2 in the Supporting Information.

Construction of Core Peptide Mutants. Primers used for plasmid constructions are listed in Table S3 in the Supporting Information. A PCR fragment was generated using primers 24 and 25 and plasmid PMA997 as a template. The fragment was digested with BamHI and EcoRI and ligated into accordingly digested plasmid PMA1304 to obtain plasmid PMA1471 encoding His8-tagged wildtype OphMA.

The plasmids encoding the OphMA core peptide mutants were generated using overlap extension PCR and plasmid PMA1471 as a template. A first PCR product for overlap extension was generated using primer 27 , together with $28,30,32,34,36,38,40,42,44,46$, $48,50,52,54,56$, or 58 . A second PCR product was obtained using primer 26 , in combination with $29,31,33,35,37,39,41,43,45,47$, $49,51,53,55,57$, or 59 . The resulting PCR products were assembled using the external primers 27 and 26. After digestion with HindIII and $B a m H I$, the resulting fragments were ligated with the accordingly digested plasmid PMA1304.

The plasmids encoding the OphMA Pro mutants were created by the Phusion Site-Directed Mutagenesis Kit (Thermo Fisher Scientific), using plasmid PMA1004 as template and respective primer pairs according to the manufacturer's protocol.

A TEV cleavage site was introduced after the His8-tag into constructs coding for the wild-type versions of both full-length OphMA and OphMA $\Delta$ C6 using PMA1004 as a template. ${ }^{24,33}$ The resulting plasmids were used as template to generate OphMA core 
peptide mutants for in vitro assays and crystallization by a reported protocol. ${ }^{26,33}$ Plasmids were sequenced using T7 primers.

Protein Production. Protein production was performed as described in refs 24 and 26, with small modifications. A preculture was grown in LB medium containing $50 \mu \mathrm{g} / \mathrm{mL}$ kanamycin at $37^{\circ} \mathrm{C}$. The main cultures were inoculated to $\mathrm{OD}_{600}$ of 0.01 in $1 \mathrm{~L}$ of $\mathrm{TB}$ medium $(2.4 \%(\mathrm{w} / \mathrm{v})$ yeast extract (Oxoid AG), $1.2 \%(\mathrm{w} / \mathrm{v})$ Tryptone (Oxoid AG), additionally containing $0.4 \%(\mathrm{w} / \mathrm{v})$ glycerol, $0.17 \mathrm{M} \mathrm{KH}_{2} \mathrm{PO}_{4}$ and $0.72 \mathrm{M} \mathrm{K}_{2} \mathrm{HPO}_{4}$ ) supplied with $50 \mu \mathrm{g} / \mathrm{mL}$ kanamycin. For full methylation, cultures were grown at $37{ }^{\circ} \mathrm{C}$ to $\mathrm{OD}_{600}=1.5-2$ and chilled on ice before induction with $0.2 \mathrm{mM}$ isopropyl- $\beta$-D-thiogalactopyranoside (IPTG), which was followed by incubation for $72 \mathrm{~h}$ at $16^{\circ} \mathrm{C}$. OphMA mutants used for in vitro assay and crystallization were expressed for $20 \mathrm{~h}$ at $16{ }^{\circ} \mathrm{C} .{ }^{26}$ In vitro methylation was performed as previously described. ${ }^{26}$

Protein Purification. Protein purification was performed as described previously, ${ }^{24,26}$ with small modifications. After induction for the required amount of time, the bacterial cells were spun down at $8000 \mathrm{~g}$ for $5 \mathrm{~min}$ at $4{ }^{\circ} \mathrm{C}$. The cell pellets were resuspended in $25 \mathrm{mM}$ Tris- $\mathrm{HCl}(\mathrm{pH} 8.0)$ additionally containing $100 \mathrm{mM} \mathrm{NaCl}, 10 \%(\mathrm{v} / \mathrm{v})$ glycerol, and $20 \mathrm{mM}$ imidazole. After a freeze-thaw cycle, $0.2 \mathrm{mg} / \mathrm{mL}$ lysozyme and EDTA-free cocktail protease inhibitor (Roche) was added and incubated for $1 \mathrm{~h}$ on ice. Cells were disrupted using a French press, and the debris was removed by centrifugation at $13000 \mathrm{~g}$ for $30 \mathrm{~min}$. After that, the cell supernatant was equilibrated with rotation with Ni-NTA beads (Thermo Scientific) at $4{ }^{\circ} \mathrm{C}$ for $1 \mathrm{~h}$. The collected beads were washed, and the protein was eluted in $25 \mathrm{mM}$ Tris- $\mathrm{HCl}(\mathrm{pH} 8.0)$ containing an additional $100 \mathrm{mM} \mathrm{NaCl}, 10 \%$ (v/ v) glycerol, and $400 \mathrm{mM}$ imidazole.

The sample was concentrated using an Amicon Ultra-4 centrifugal filter device with a molecular-weight cutoff of $30 \mathrm{kDa}$ (Millipore). One milliliter $(1 \mathrm{~mL})$ of protein sample was loaded into a Superdex200 Increase column (GE Healthcare), which was pre-equilibrated with $25 \mathrm{mM}$ Tris- $\mathrm{HCl}$ ( $\mathrm{pH} \mathrm{8.0)}$ ), 10\% (v/v) glycerol, and $100 \mathrm{mM}$ $\mathrm{NaCl}$. Protein concentration was determined using the Pierce BCA protein assay (Thermo Scientific) and bovine serum albumin as a standard.

All proteins were further purified by gel filtration as described previously ${ }^{26}$ and used fresh or stored at $-80{ }^{\circ} \mathrm{C}$.

HPLC-ESI-MS/MS High-Energy Collision Dissociation (HCD). The C-terminal tryptic peptides of OphMA variants were analyzed by HPLC-ESI MS/MS as described previously. ${ }^{24}$ The purified proteins were concentrated to $4 \mathrm{mg} \mathrm{mL}^{-1}$ in $25 \mathrm{mM}$ Tris- $\mathrm{HCl}(\mathrm{pH} 8.0), 10 \%$ (v/v) glycerol and $100 \mathrm{mM} \mathrm{NaCl}$ and supplied with protease. All mutants except for Arg mutants were supplied with trypsin in a molar ratio of $1: 80$ and incubated in a glass vial for $16 \mathrm{~h}$ at $37^{\circ} \mathrm{C}$ in a final volume of $20 \mu \mathrm{L}$. Arg mutants were treated with endoproteinase Lys$\mathrm{C}$ in a molar ratio of $1: 20$ and incubated at $37^{\circ} \mathrm{C}$ for $16-24 \mathrm{~h}$ in a final volume of $27.5 \mu \mathrm{L}$.

After proteolytic digestion, 3 or $5 \mu \mathrm{L}$ of sample was used for MS/ MS analysis. The resulting peptides were separated in increasing acetonitrile gradient on the Phenomenex Kinetex $2.6 \mu \mathrm{m} \mathrm{C18}$ column $(150 \mathrm{~mm} \times 2.1 \mathrm{~mm})$ on Dionex Ultimate 3000 UHPLC system and subsequently analyzed with targeted MS/MS using Thermo Scientific Q Exactive mass spectrometer. ${ }^{24}$

In vitro methylated proteins were digested at $37^{\circ} \mathrm{C}$ overnight using sequencing-grade trypsin (Promega). Data were recorded on a Sciex $5600+$ mass spectrometer equipped with the Eksigent 2D Ultra NanoLC system using a Thermo Scientific PepMap C18 column (75 $\mu \mathrm{m} \times 15 \mathrm{~cm})$ and trap $(2 \mathrm{~cm})$. MS/MS data were extracted using the SCIEX PeakView software and analyzed using the Mascot 2.6 search engine (Matrix Science) against sequences of OphMA mutants. MS/ MS interpretation was verified manually.

Crystallization, Data Collection, and Structure Determination. Freshly prepared V404F, V404E, V406P, and I407P were crystallized by mixing $1 \mu \mathrm{L}$ of protein $(30-50 \mathrm{mg} / \mathrm{mL})$ preincubated with $3 \mathrm{mM}$ SAM with $1 \mu \mathrm{L}$ of reservoir solution (0.3-0.4 M KSCN, 1.8-2.4 $\mathrm{M}$ sodium malonate, and $0.1 \mathrm{M}$ bicine buffer $\mathrm{pH} 8.5-9.3)$ ). Crystals were obtained at $16^{\circ} \mathrm{C}$ within 1 week using the hanging drop diffusion method. These crystals were flash frozen in the cryo protectant containing 0.1 M bicine ( $\mathrm{pH} 9.0$ ), 0.3 M KSCN, and 2.53.0 M sodium malonate.

X-ray diffraction data were recorded at Diamond Light Source beamline I03 (V404E and V406P), I24 ( $\Delta$ C6-V404F), or I04 (I407P). Data were reduced, integrated, and scaled using xia2. ${ }^{34}$ The structures were solved by molecular replacement with OphMA $\Delta \mathrm{C} 18$ (PDB ID: 5NOO) as the initial search model using Phaser $^{35}$ Structures were further refined and improved using Coot, ${ }^{36}$ refmac, $^{37}$ and PDB_REDO. ${ }^{38}$ The final models were verified with MolProbity. ${ }^{39}$ The statistics of the data collection and refinement are summarized in Table S1 in the Supporting Information. All crystallographic figures were generated using Pymol (Schrödinger).

\section{ASSOCIATED CONTENT}

\section{Supporting Information}

The Supporting Information is available free of charge at https://pubs.acs.org/doi/10.1021/acschembio.0c00237.

MS/MS fragmentation results of C-terminal peptides in in vivo assays (Figure S1); MS/MS fragmentation results of C-terminal peptides (most methylated and most abundant species) for OphMA variants in in vitro assays (Figure S2); $\sigma \mathrm{A}$-weighted 2Fo-Fc electron density map (contoured at $1 \sigma$ ) showing the substrate peptide (Figure S3); data collection and refinement statistics (Table S1); list of plasmids (Table S2); and list of primers (Table S3) (PDF)

\section{Accession Codes}

Coordinates have been deposited in the Protein Data Bank, with accession codes 6QZY (V406P with SAH), 6QZZ (V404E with SAH), 6R00 ( $\triangle \mathrm{C} 6-\mathrm{V} 404 \mathrm{~F}$ with SAH), and 6TSC (I407P with SAH).

\section{AUTHOR INFORMATION}

\section{Corresponding Authors}

James H. Naismith - Division of Structural Biology, Wellcome Trust Centre of Human Genomics, Oxford OX3 7BN, United Kingdom; Research Complex at Harwell, Rutherford Laboratory, Didcot, Oxfordshire OX11 OFA, United Kingdom; Rosalind Franklin Institute, Rutherford Laboratory, Didcot,

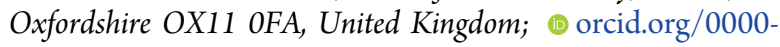
0001-6744-5061; Email: naismith@strubi.ox.ac.uk

Markus Künzler - Institute of Microbiology, Department of Biology, Eidgenössische Technische Hochschule (ETH) Zürich, Zürich, Switzerland; @orcid.org/0000-0003-1275-0629; Email: mkuenzle@ethz.ch

\section{Authors}

Haigang Song - Division of Structural Biology, Wellcome Trust Centre of Human Genomics, Oxford OX3 7BN, United Kingdom; Research Complex at Harwell, Rutherford Laboratory, Didcot, Oxfordshire OX11 OFA, United Kingdom; (1) orcid.org/0000-0002-7568-0544

Jūratè Fahrig-Kamarauskaitè - Institute of Microbiology, Department of Biology, Eidgenössische Technische Hochschule (ETH) Zürich, Zürich, Switzerland

Emmanuel Matabaro - Institute of Microbiology, Department of Biology, Eidgenössische Technische Hochschule (ETH) Zürich, Zürich, Switzerland

Hannelore Kaspar - Institute of Microbiology, Department of Biology, Eidgenössische Technische Hochschule (ETH) Zürich, Zürich, Switzerland 
Sally L. Shirran - Biomedical Sciences Research Complex, North Haugh, University of St. Andrews, Fife KY16 9ST, United Kingdom

Christina Zach - Institute of Microbiology, Department of Biology, Eidgenössische Technische Hochschule (ETH) Zürich, Zürich, Switzerland

Amy Pace - Institute of Microbiology, Department of Biology, Eidgenössische Technische Hochschule (ETH) Zürich, Zürich, Switzerland

Bozhidar-Adrian Stefanov - Institute of Microbiology, Department of Biology, Eidgenössische Technische Hochschule (ETH) Zürich, Zürich, Switzerland

Complete contact information is available at:

https://pubs.acs.org/10.1021/acschembio.0c00237

\section{Author Contributions}

J.F.K., H.S., E.M., C.Z., A.P., and B-A.S. designed, constructed, produced and purified the mutant proteins. H.S. performed the in vitro methylation experiments. J.F.K., H.S., C.Z., H.K., and S.L.S performed mass spectrometric assays. J.H.N. and H.S. performed the structural biology experiments. J.H.N. and M.K. initiated and supervised the project. All authors contributed to the writing of the manuscript and analysis of the data.

\section{Author Contributions}

${ }^{\ddagger}$ These authors contributed equally to this work.

\section{Funding}

This work was financially supported by the Commission for Technology and Innovation (CTI/Innosuisse Grant No. CTI 25951.2), the Swiss National Science Foundation (Grant No. 31003A_173097), Wellcome Trust (Grant No. 094476/Z/10/ Z), and BBSRC (Grant No. BB/R018189/1).

\section{Notes}

The authors declare the following competing financial interest(s): M. Kunzler is co-inventor of the World Intellectual Property Organization patent WO2017174760A1.

\section{REFERENCES}

(1) Zorzi, A., Deyle, K., and Heinis, C. (2017) Cyclic peptide therapeutics: past, present and future. Curr. Opin. Chem. Biol. 38, 2429.

(2) Räder, A. F. B., Weinmüller, M., Reichart, F., SchumacherKlinger, A., Merzbach, S., Gilon, C., Hoffman, A., and Kessler, H. (2018) Orally active peptides: is there a magic bullet? Angew. Chem., Int. Ed. 57, 14414-14438.

(3) Hickey, J. L., Zaretsky, S., St. Denis, M. A., Kumar Chakka, S., Morshed, M. M., Scully, C. C. G., Roughton, A. L., and Yudin, A. K. (2016) Passive membrane permeability of macrocycles can be controlled by exocyclic amide bonds. J. Med. Chem. 59, 5368-5376.

(4) Furukawa, A., Townsend, C. E., Schwochert, J., Pye, C. R., Bednarek, M. A., and Lokey, R. S. (2016) Passive membrane permeability in cyclic peptomer scaffolds is robust to extensive variation in side chain functionality and backbone geometry. J. Med. Chem. 59, 9503-9512.

(5) Rezai, T., Yu, B., Millhauser, G. L., Jacobson, M. P., and Lokey, R. S. (2006) Testing the conformational hypothesis of passive membrane permeability using synthetic cyclic peptide diastereomers. J. Am. Chem. Soc. 128, 2510-2511.

(6) Wang, C. K., Northfield, S. E., Colless, B., Chaousis, S., Hamernig, I., Lohman, R.-J., Nielsen, D. S., Schroeder, C. I., Liras, S., Price, D. A., Fairlie, D. P., and Craik, D. J. (2014) Rational design and synthesis of an orally bioavailable peptide guided by NMR amide temperature coefficients. Proc. Natl. Acad. Sci. U. S. A. 111, 1750417509.
(7) Schwochert, J., Lao, Y., Pye, C. R., Naylor, M. R., Desai, P. V., Gonzalez Valcarcel, I. C., Barrett, J. A., Sawada, G., Blanco, M.-J., and Lokey, R. S. (2016) Stereochemistry balances cell permeability and solubility in the naturally derived phepropeptin cyclic peptides. ACS Med. Chem. Lett. 7, 757-761.

(8) Rand, A. C., Leung, S. S. F., Eng, H., Rotter, C. J., Sharma, R. Kalgutkar, A. S., Zhang, Y., Varma, M. V., Farley, K. A., Khunte, B., Limberakis, C., Price, D. A., Liras, S., Mathiowetz, A. M., Jacobson, M. P., and Lokey, R. S. (2012) Optimizing PK properties of cyclic peptides: the effect of side chain substitutions on permeability and clearance(). MedChemComm 3, 1282-1289.

(9) Matsui, K., Kido, Y., Watari, R., Kashima, Y., Yoshida, Y., and Shuto, S. (2017) Highly Conformationally Restricted Cyclopropane Tethers with Three-Dimensional Structural Diversity Drastically Enhance the Cell Permeability of Cyclic Peptides. Chem. - Eur. J. 23, 3034-3041.

(10) Bockus, A. T., Schwochert, J. A., Pye, C. R., Townsend, C. E., Sok, V., Bednarek, M. A., and Lokey, R. S. (2015) Going Out on a Limb: Delineating The Effects of $\beta$-Branching, N-Methylation, and Side Chain Size on the Passive Permeability, Solubility, and Flexibility of Sanguinamide A Analogues. J. Med. Chem. 58, 7409-7418.

(11) Chatterjee, J., Gilon, C., Hoffman, A., and Kessler, H. (2008) $\mathrm{N}$-methylation of peptides: a new perspective in medicinal chemistry. Acc. Chem. Res. 41, 1331-1342.

(12) Chatterjee, J., Rechenmacher, F., and Kessler, H. (2013) Nmethylation of peptides and proteins: an important element for modulating biological functions. Angew. Chem., Int. Ed. 52, 254-269.

(13) Räder, A. F. B., Reichart, F., Weinmüller, M., and Kessler, H. (2018) Improving oral bioavailability of cyclic peptides by $\mathrm{N}$ methylation. Bioorg. Med. Chem. 26, 2766-2773.

(14) Ovadia, O., Greenberg, S., Chatterjee, J., Laufer, B., Opperer, F., Kessler, H., Gilon, C., and Hoffman, A. (2011) The effect of multiple $\mathrm{N}$-methylation on intestinal permeability of cyclic hexapeptides. Mol. Pharmaceutics 8, 479-487.

(15) Müller, M. M. (2018) Post-Translational Modifications of Protein Backbones: Unique Functions, Mechanisms, and Challenges. Biochemistry 57, 177-185.

(16) Bock, J. E., Gavenonis, J., and Kritzer, J. A. (2013) Getting in shape: controlling peptide bioactivity and bioavailability using conformational constraints. ACS Chem. Biol. 8, 488-499.

(17) Scherer, G., Kramer, M. L., Schutkowski, M., Reimer, U., and Fischer, G. (1998) Barriers to rotation of secondary amide peptide bonds. J. Am. Chem. Soc. 120, 5568-5574.

(18) Sharma, A., Kumar, A., Abdel Monaim, S. A. H., Jad, Y. E., ElFaham, A., de la Torre, B. G., and Albericio, F. (2018) N-methylation in amino acids and peptides: Scope and limitations. Biopolymers 109, No. e23110.

(19) Yamagishi, Y., Shoji, I., Miyagawa, S., Kawakami, T., Katoh, T., Goto, Y., and Suga, H. (2011) Natural product-like macrocyclic Nmethyl-peptide inhibitors against a ubiquitin ligase uncovered from a ribosome-expressed de novo library. Chem. Biol. 18, 1562-1570.

(20) Mayer, A., Anke, H., and Sterner, O. (1997) Omphalotin, A New Cyclic Peptide with Potent Nematicidal Activity from Omphalotus olearius I. Fermentation and Biological Activity. Nat. Prod. Lett. 10, 25-32.

(21) Sterner, O., Etzel, W., Mayer, A., and Anke, H. (1997) Omphalotin, A New Cyclic Peptide with Potent Nematicidal Activity from Omphalotus Olearius II. Isolation and Structure Determination. Nat. Prod. Lett. 10, 33-38.

(22) Büchel, E., Martini, U., Mayer, A., Anke, H., and Sterner, O. (1998) Omphalotins B, C and D, nematicidal cyclopeptides from Omphalotus olearius. Absolute configuration of omphalotin A. Tetrahedron 54, 5345-5352.

(23) Liermann, J. C., Opatz, T., Kolshorn, H., Antelo, L., Hof, C., and Anke, H. (2009) Omphalotins E-I, Five Oxidatively Modified Nematicidal Cyclopeptides from Omphalotus olearius. Eur. J. Org. Chem. 2009, 1256-1262.

(24) van der Velden, N. S., Kälin, N., Helf, M. J., Piel, J., Freeman, M. F., and Künzler, M. (2017) Autocatalytic backbone N-methylation 
in a family of ribosomal peptide natural products. Nat. Chem. Biol. 13, 833-835.

(25) Ramm, S., Krawczyk, B., Mühlenweg, A., Poch, A., Mösker, E., and Süssmuth, R. D. (2017) A Self-Sacrificing N-Methyltransferase Is the Precursor of the Fungal Natural Product Omphalotin. Angew. Chem., Int. Ed. 56, 9994-9997.

(26) Song, H., van der Velden, N. S., Shiran, S. L., Bleiziffer, P., Zach, C., Sieber, R., Imani, A. S., Krausbeck, F., Aebi, M., Freeman, M. F., Riniker, S., Künzler, M., and Naismith, J. H. (2018) A molecular mechanism for the enzymatic methylation of nitrogen atoms within peptide bonds. Sci. Adv. 4, No. eaat 2720 .

(27) Ongpipattanakul, C., and Nair, S. K. (2018) Molecular Basis for Autocatalytic Backbone N-Methylation in RiPP Natural Product Biosynthesis. ACS Chem. Biol. 13, 2989-2999.

(28) Quijano, M. R., Zach, C., Miller, F. S., Lee, A. R., Imani, A. S., Künzler, M., and Freeman, M. F. (2019) Distinct Autocatalytic $\alpha$ - NMethylating Precursors Expand the Borosin RiPP Family of Peptide Natural Products. J. Am. Chem. Soc. 141, 9637-9644.

(29) Sarkar, S. K., Young, P. E., Sullivan, C. E., and Torchia, D. A. (1984) Detection of cis and trans X-Pro peptide bonds in proteins by 13C NMR: application to collagen. Proc. Natl. Acad. Sci. U. S. A. 81, $4800-4803$.

(30) Joseph, A. P., Srinivasan, N., and de Brevern, A. G. (2012) Cistrans peptide variations in structurally similar proteins. Amino Acids 43, 1369-1381.

(31) Vogt, E., and Künzler, M. (2019) Discovery of novel fungal RiPP biosynthetic pathways and their application for the development of peptide therapeutics. Appl. Microbiol. Biotechnol. 103, 5567-5581. (32) Sambrook, J. (2001) Molecular Cloning: A Laboratory Manual, 3rd Edition; Cold Spring Harbor Laboratory Press: Cold Spring Harbor, NY; p 2344 (three-volume set).

(33) Liu, H., and Naismith, J. H. (2008) An efficient one-step sitedirected deletion, insertion, single and multiple-site plasmid mutagenesis protocol. BMC Biotechnol. 8, 91.

(34) Winter, G. (2010) xia2: an expert system for macromolecular crystallography data reduction. J. Appl. Crystallogr. 43, 186-190.

(35) McCoy, A. J., Grosse-Kunstleve, R. W., Adams, P. D., Winn, M. D., Storoni, L. C., and Read, R. J. (2007) Phaser crystallographic software. J. Appl. Crystallogr. 40, 658-674.

(36) Emsley, P., Lohkamp, B., Scott, W. G., and Cowtan, K. (2010) Features and development of Coot. Acta Crystallogr., Sect. D: Biol. Crystallogr. 66, 486-501.

(37) Murshudov, G. N., Vagin, A. A., and Dodson, E. J. (1997) Refinement of macromolecular structures by the maximum-likelihood method. Acta Crystallogr., Sect. D: Biol. Crystallogr. 53, 240-255.

(38) Joosten, R. P., Long, F., Murshudov, G. N., and Perrakis, A. (2014) The PDB_REDO server for macromolecular structure model optimization. IUCrJ 1, 213-220.

(39) Chen, V. B., Arendall, W. B., Headd, J. J., Keedy, D. A., Immormino, R. M., Kapral, G. J., Murray, L. W., Richardson, J. S., and Richardson, D. C. (2010) MolProbity: all-atom structure validation for macromolecular crystallography. Acta Crystallogr., Sect. D: Biol. Crystallogr. 66, 12-21. 